\title{
DESIGN E PARAGOMINAS: UM ESTUDO SOBRE A RELAÇÃO DA PROFISSÃO E A SOCIEDADE LOCAL
}

\author{
Ruanderson Silva Dias \\ Universidade do Estado do Pará \\ ruanderson_dias@hotmail.com \\ Tarlany Pezzin Moreira \\ Universidade do Estado do Pará \\ tarlanypezzin@hotmail.com \\ João Roberto dos Santos Soares \\ Universidade do Estado do Pará \\ sansoar.design@gmail.com
}

Resumo: A presente pesquisa teve por finalidade promover alguns conceitos de Design à população de Paragominas, observar o seu comportamento e recolher dados que possam contribuir para os profissionais da área, servindo como fonte para o direcionamento quanto às expectativas de atuação no município. Ficou demonstrado que existe uma dificuldade em encontrar espaços de atuação no mercado local, além de algum desconhecimento com relação a própria profissão. A atividade que desenvolve projetos tem se tornado cada vez mais estratégica para o crescimento econômico e para a manutenção de um desenvolvimento sustentável e socialmente justo. No município de Paragominas, considerado modelo de gestão ambiental, foi somente no final do ano de 2014 que se formaram os primeiros profissionais em Design pela Universidade do Estado do Pará - Campus VI. Nesse sentido, buscou-se interpretar a partir de entrevistas com figuras empresariais e administrativas, palestras informativas e questionários com alunos do ensino básico da rede pública do município, a absorção de tais conhecimentos, analisando a figura do profissional do Design dentro desse contexto. Foram elaborados em seguida, gráficos ilustrativos da pesquisa, tabulando os dados de maneira que fosse possível entender alguns aspectos da sociedade local, o comportamento do mercado de trabalho e a educação praticada nas escolas, em uma projeção da perspectiva da escolha da carreira pelas gerações que se formam. Além disso, tal processo conduziu a sugestão de iniciativas que futuramente possam intervir, esclarecer e conscientizar todos os setores possíveis da relevância cada vez significativa da profissão na cidade de Paragominas.

Palavras-chave: design e sociedade, educação, Paragominas 